\title{
Effect of the pattern of food intake on human energy metabolism
}

\author{
BY WILHELMINE P. H. G. VERBOEKET-VAN DE VENNE', \\ KLAAS R. WESTERTERP' AND ARNOLD D. M. KESTER ${ }^{2}$ \\ Departments of ${ }^{1}$ Human Biology and ${ }^{2}$ Medical Informatics and Statistics, University of Limburg, \\ P.O. Box 616, 6200 MD Maastricht. The Netherlands
}

(Received 10 May 1991 - Accepted 7 September 1992)

\begin{abstract}
The pattern of food intake can affect the regulation of body weight and lipogenesis. We studied the effect of meal frequency on human energy expenditure (EE) and its components. During 1 week ten male adults (age 25-61 years, body mass index $20 \cdot 7-30 \cdot 4 \mathrm{~kg} / \mathrm{m}^{2}$ ) were fed to energy balance at two meals/d (gorging pattern) and during another week at seven meals/d (nibbling pattern). For the first $6 \mathrm{~d}$ of each week the food was provided at home, followed by a $36 \mathrm{~h}$ stay in a respiration chamber. $\mathrm{O}_{2}$ consumption and $\mathrm{CO}_{2}$ production (and hence EE) were calculated over $24 \mathrm{~h}$. EE in free-living conditions was measured over the 2 weeks with doubly-labelled water (average daily metabolic rate, ADMR). The three major components of ADMR are basal metabolic rate (BMR), diet-induced thermogenesis (DIT) and EE for physical activity (ACT). There was no significant effect of meal frequency on $24 \mathrm{~h} \mathrm{EE}$ or ADMR. Furthermore, BMR and ACT did not differ between the two patterns. DIT was significantly elevated in the gorging pattern, but this effect was neutralized by correction for the relevant time interval. With the method used for determination of DIT no significant effect of meal frequency on the contribution of DIT to ADMR could be demonstrated.
\end{abstract}

Meal frequency: Energy expenditure: Free-living conditions: Diet-induced thermogenesis

The pattern of food intake, i.e. the feeding frequency, has a considerable effect on the body composition of experimental animals. If rats which normally eat six to eight meals/d (nibbling pattern) are trained to eat only once or twice daily (gorging pattern) their body fat mass will increase (Cohn et al. 1965; Fábry \& Tepperman, 1970; Leveille, 1970; Tepperman \& Tepperman, 1970). Cohn et al. (1965) conducted some studies on tube-fed rats: rats in one group were allowed to eat ad lib. and rats in a second group were fed on an identical quantity of food by stomach-tube twice daily. At the end of the experiment the animals which received their food by stomach-tube had nearly twice as much body fat as did the rats allowed to eat ad lib.

In man, meal frequency is often cited as one of the variables that can influence energy balance. It has been observed that obese individuals often skip breakfast (Huenemann $e t$ al. 1966) and tend to eat most of their food in one meal, usually in the late afternoon or evening (Huenemann, 1972). Using epidemiological methods, Fábry and co-workers studied the relationship between meal frequency and obesity. Hejda \& Fábry (1964) reported a higher energy intake (EI) in subjects consuming their food in a greater number of meals. However, body weight was highest in the group who ate the fewest meals and had the lowest EI. In a survey of elderly men, Fábry et al. (1964) found that subjects who ate one or two meals/d tended to be more overweight than those who ate three or more meals/d. Fábry et al. (1966) confirmed this finding in a study of schoolchildren. Metzner et al. (1977) studied the relationship between meal frequency and adiposity in subjects with the same total daily food intake and showed that those who ate more frequently during a $24 \mathrm{~h}$ period had less adipose tissue than those who ate less frequently. 
Furthermore, a gorging pattern of food intake has been shown to enhance lipogenesis (Fábry et al. 1964; Terpstra et al. 1978), increase body weight (Dallosso et al. 1982), increase blood serum cholesterol level (Gwinup et al. $1963 \mathrm{a}$; Cohn, 1964; Jagannathan et al. 1964; Irwin \& Feeley, 1967; Young et al. 1972) and reduce glucose tolerance (Gwinup et al. 1963b; Young et al. 1972; Debry et al. 1973; Fábry, 1973).

Studies of the effect of meal frequency on $24 \mathrm{~h}$ energy expenditure (EE) and its components basal metabolic rate (BMR), diet-induced thermogenesis (DIT) and EE due to physical activity (ACT) have been inconsistent. In a previous study, in which we investigated the short-term $(2 \mathrm{~d})$ effect of meal frequency on energy metabolism, we observed an increased EE during the postprandial hours on a gorging pattern, indicating a greater contribution of DIT to 24 h EE (Verboeket-van de Venne \& Westerterp, 1991). In view of the fact that $24 \mathrm{~h}$ EE was not affected by the meal frequency, this would suggest that ACT was decreased on a gorging pattern.

The present study was conducted to investigate whether there is an effect of the pattern of food intake on $24 \mathrm{~h}$ energy metabolism (in both free-living and experimentallycontrolled conditions) and, more specifically, on the components of EE: BMR, DIT and ACT.

\section{METHODS \\ Subjects}

Ten healthy male adults volunteered for this investigation. Their physical characteristics are presented in Table 1. They were all non-smokers. The procedures to be used in the study were carefully explained to each subject before he gave his consent to participate. The protocol was reviewed and approved by the University of Limburg Ethical Committee.

\section{Experimental design}

The experiment was conducted over two consecutive weeks, during one of which daily intake was consumed at two meals (gorging pattern) and during the other at seven meals (nibbling pattern). The order of administration of the gorging and nibbling patterns was randomized, with six subjects receiving the gorging pattern first and four the nibbling pattern. For the first $6 \mathrm{~d}$ of each week food was provided at home for consumption according to the prescribed eating pattern (gorging or nibbling). On the last day of each week the subjects stayed in a respiration chamber in which $\mathrm{O}_{2}$ consumption, $\mathrm{CO}_{2}$ production and physical activity were measured (see p. 106). Subjects were fed to energy balance basing the average daily energy requirement on a $7 \mathrm{~d}$ food record, filled out 1-15 weeks before the experimental period. During these seven consecutive days subjects recorded their food intake in a diary that was divided into seven periods/d (three meals, four inter-meal periods). Over the 2-week experimental period data were collected on EI, EE, and changes in body mass and body composition. Fig. 1 illustrates the experimental design schematically.

\section{Eating patterns}

The two eating patterns were characterized by a minimal or maximal spreading of the EI throughout the day. The gorging pattern consisted of two large meals: lunch at 12.00 hours with bread, fruit and orange juice, containing $40 \%$ of the daily EI; and dinner plus dessert at 18.00 hours, containing the remaining $60 \%$. The nibbling pattern consisted of seven small meals: breakfast at 07.30 hours ( $15 \%$ daily EI), a morning snack at 10.00 hours ( $10 \%$ daily EI), lunch at 12.00 ( $25 \%$ daily EI), a dessert at 14.00 hours ( $10 \%$ daily EI), a piece of fruit at 16.00 hours ( $5 \%$ daily EI), a small dinner at 18.00 hours ( $25 \%$ daily EI) and an evening snack at 20.30 hours ( $10 \%$ daily EI). Subjects were instructed to consume all food items and return any leftovers. 
Table 1. Physical characteristics of the subjects and order of treatment*

\begin{tabular}{cccccc}
\hline Subject & $\begin{array}{c}\text { Age } \\
\text { (years) }\end{array}$ & $\begin{array}{c}\text { Height } \\
(\mathrm{m})\end{array}$ & $\begin{array}{c}\mathrm{Wt} \\
(\mathrm{kg})\end{array}$ & $\begin{array}{c}\text { BMI } \\
\left(\mathrm{kg} / \mathrm{m}^{2}\right)\end{array}$ & $\begin{array}{c}\text { Order of } \\
\text { treatment }\end{array}$ \\
\hline 1 & 46 & $1 \cdot 79$ & $97 \cdot 3$ & $30 \cdot 4$ & $\mathrm{G}-\mathrm{N}$ \\
2 & 53 & $1 \cdot 79$ & $80 \cdot 7$ & $25 \cdot 2$ & $\mathrm{G}-\mathrm{N}$ \\
3 & 43 & 1.65 & $57 \cdot 5$ & $21 \cdot 1$ & $\mathrm{~N}-\mathrm{G}$ \\
4 & 31 & $1 \cdot 89$ & $76 \cdot 3$ & $21 \cdot 4$ & $\mathrm{~N}-\mathrm{G}$ \\
5 & 61 & $1 \cdot 76$ & $89 \cdot 4$ & $28 \cdot 9$ & $\mathrm{G}-\mathrm{N}$ \\
6 & 33 & $1 \cdot 76$ & 74.5 & $24 \cdot 1$ & $\mathrm{G}-\mathrm{N}$ \\
7 & 38 & $1 \cdot 73$ & $67 \cdot 0$ & $22 \cdot 4$ & $\mathrm{~N}-\mathrm{G}$ \\
8 & 25 & $1 \cdot 75$ & $63 \cdot 5$ & $20 \cdot 7$ & $\mathrm{~N}-\mathrm{G}$ \\
9 & 60 & 1.60 & $75 \cdot 3$ & $29 \cdot 4$ & $\mathrm{G}-\mathrm{N}$ \\
10 & 36 & $1 \cdot 80$ & 86.4 & $26 \cdot 7$ & $\mathrm{G}-\mathrm{N}$ \\
\hline
\end{tabular}

BMI, body mass index; G, gorging pattern; N, nibbling pattern.

* For details of diets and procedures, see p. 104.
Body wt
$\mathrm{X}$
$x \times$
$x \times$
Respiration chamber
$\square$

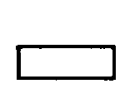

Meal pattern*

\begin{tabular}{|l|l|}
\hline Gorging & Nibbling \\
\hline
\end{tabular}

Urine samples

Experimental day

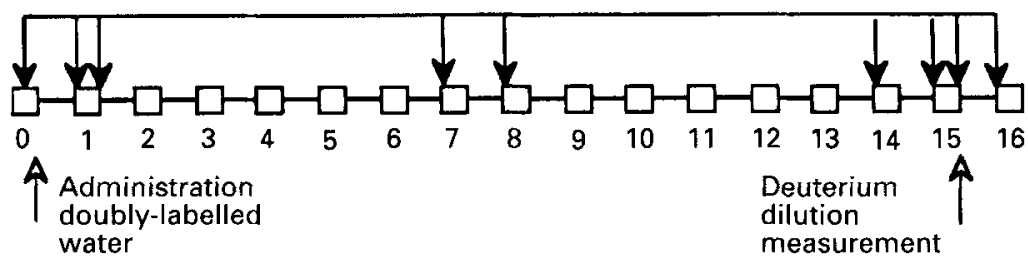

Fig. 1. Experimental design of the study. ${ }^{*}$ Order reversed for four subjects.

The total daily menu, macronutrient composition and EI were the same for the two eating patterns. The food provided $16 \%$ energy as protein, $38 \%$ as fat and $46 \%$ as carbohydrate. The value of the food quotient (FQ) as defined by Flatt (1987) was 0.85 .

\section{Measurement of $E E$}

EE was measured over the two consecutive weeks of the experimental period with doublylabelled water (average daily metabolic rate, ADMR) and on the last day of each week in a respiration chamber ( $24 \mathrm{~h} \mathrm{EE}$ ). Thus, ADMR was measured under free-living conditions. The $24 \mathrm{~h}$ EE measurement allowed separate assessment of the BMR and DIT (see p. 106), permitting calculation of $A C T$ as $A D M R-(B M R+D I T)$. In the present study we measured the sleeping metabolic rate (SMR) and have assumed this to be $5 \%$ less than BMR, which is higher on account of the energy cost of arousal (Goldberg et al. 1988).

\section{Determination of $A D M R$}

ADMR was measured throughout the $14 \mathrm{~d}$ of the study using the doubly-labelled water technique (Westerterp et al. 1986). Before going to bed at night on day 0 the subjects ingested a ${ }^{2} \mathrm{H}_{2}{ }^{18} \mathrm{O}$ drink after emptying the bladder (baseline urine sample). The dosage was 
based on body mass in order to create a ${ }^{2} \mathrm{H}$ excess of 150 p.p.m. and an ${ }^{18} \mathrm{O}$ excess of 300 p.p.m. Further urine samples were collected by the subjects at home on day 1 in the morning after the first voiding, on day 1 before going to bed at night, and during the stay in the respiration chamber on days $7,8,14$ and 15 in the morning after the first voiding. Isotope abundances in the urine samples were measured with an isotope-ratio mass spectrometer (VG Isogas, Aqua Sira; VG Isogas Ltd, Middlewich, Cheshire). $\mathrm{CO}_{2}$ production was calculated as the difference between the disappearance rates of ${ }^{18} \mathrm{O}$ and ${ }^{2} \mathrm{H}$, correcting for isotope fractionation and isotope incorporation in other compartments than $\mathrm{H}_{2} \mathrm{O}$ (Westerterp \& Saris, 1991). Assessment of ADMR was based on this $\mathrm{CO}_{2}$ production using an energy equivalent of $531 \mathrm{~kJ} / \mathrm{mol}$ (RQ 0.85 ), according to the average $\mathrm{FQ}$ calculated from the macronutrient composition of the diet.

\section{Determination of $24 \mathrm{~h} \mathrm{EE}, B M R, D I T$ and $A C T$}

EE was calculated according to Weir (1949) from $\mathrm{O}_{2}$ consumption and $\mathrm{CO}_{2}$ production as measured in a respiration chamber (Schoffelen et al. 1984). This chamber measures $14 \mathrm{~m}^{3}$ and is furnished with a bed, chair, table, TV, radio, telephone, wash-bowl and toilet facilities. The chamber is ventilated with fresh air at $50 \mathrm{l} / \mathrm{min}$. The ventilation rate was measured with a dry gas meter (Schlumberger, type G6; Meterfabriek Schlumberger bV, Dordrecht, The Netherlands). The concentration of $\mathrm{O}_{2}$ and $\mathrm{CO}_{2}$ was measured using a paramagnetic $\mathrm{O}_{2}$ analyser (Servomex, type OA 184; Servomex Ltd, Crowborough, Sussex) and an infrared $\mathrm{CO}_{2}$ analyser (Hartmann \& Braun, type URAS 3Gn; Hartmann \& Braun Aktiengesellschaft, Frankfurt, Germany). Ingoing air was analysed once every $15 \mathrm{~min}$ and outgoing air once every $5 \mathrm{~min}$. The gas sample to be measured was selected by a computer which also stored and processed the data. The system was checked monthly with ethanol combustion. Differences between calculated and measured $\mathrm{O}_{2}$ consumption and $\mathrm{CO}_{2}$ production were 0.5 (SD 1.2) $\%$ and -2.5 (SD 1.6) \% respectively.

$24 \mathrm{~h}$ EE was calculated from 07.00 hours to 07.00 hours. In order to describe the effect of meal frequency on EE throughout the day, EE was also calculated over $3 \mathrm{~h}$ intervals. The physical activity of the subjects was monitored by means of a radar system, based on the Doppler principle. During daytime subjects were allowed to move freely, sit, lie down, study, telephone, listen to the radio and watch television; only sleeping and strenuous exercise were not allowed. SMR was measured from 03.00 hours to 06.00 hours, when subjects were asleep. SMR was divided by 0.95 to assess BMR. The method used for determination of DIT was previously described by Schutz et al. (1984) and is based on simultaneous measurements of both physical activity and EE. The relationship between physical activity and $\mathrm{EE}$ for each individual, both averaged over $30 \mathrm{~min}$ periods, was plotted. Only the intervals after the first meal until bedtime were used, i.e. from 12.00 hours to 23.00 hours for the gorging pattern (i.e. 11 postprandial hours) and from 07.30 hours to 23.00 hours for the nibbling pattern (i.e. 15.5 postprandial hours). The intercept of the regression line at zero activity represents the $E E$ in the inactive state $\left(E_{0 \text { activity }}\right)$ consisting of two components: BMR and DIT. By subtracting BMR from $E_{\text {arctivity }}$ we obtained DIT, and corrected it for the relevant time interval (see p. 106). ACT was calculated as ADMR - BMR - DIT (corrected for time). Thus, the separate components of ADMR are obtained by the following equations:

$$
\begin{aligned}
& \mathrm{BMR}=\mathrm{SMR} / 0.95 \\
& \mathrm{DIT}=\mathrm{EE}_{\text {0activity }}-\mathrm{BMR}, \\
& \mathrm{DIT}(\text { corr. })=\left(\mathrm{EE}_{\text {0activity }}-\mathrm{BMR}\right) \times(\text { postprandial hours } / 24), \\
& \mathrm{ACT}=\mathrm{ADMR}-\mathrm{BMR}-\mathrm{DIT} \text { (corr.). }
\end{aligned}
$$




\section{Body weight and body composition}

Subjects weighed themselves (without clothing) on the mornings of days $0,7,8,14$ and 15 , after voiding and before consuming any food or drink. A digital balance (Seca delta, model 707; Vogel \& Halke, Hamburg, Germany) accurate to $0 \cdot 1 \mathrm{~kg}$ was used.

Body composition was ascertained by deuterium dilution at the start and end of the 2week experimental period. At the start body composition was assessed by analysing the urine samples collected on the evening of day 0 (baseline urine sample) and on the morning of day 1 after the first voiding. At the end of the experimental period, i.e. before going to bed at night on day 15 , a ${ }^{2} \mathrm{H}_{2} \mathrm{O}$ dilution was drunk at home after emptying the bladder (baseline urine sample). The dosage was based on body mass in order to create a ${ }^{2} \mathrm{H}$ excess of 100 p.p.m. A second urine sample was collected by the subjects at home on day 16 in the morning after the first voiding. Total body water (TBW) was calculated as the deuterium dilution space divided by 1.04 , correcting for exchange of the deuterium label with non-aqueous hydrogen of body solids (Schoeller et al. 1980). Fat-free mass (FFM) was calculated from TBW assuming a hydration coefficient of 0.73 ; fat mass (FM) was calculated as body weight minus FFM.

\section{Analysis of data}

Data on EI, EE and body composition were analysed by paired $t$ test within eating patterns. Differences between patterns were tested using the modified paired $t$ test for the crossover design as described by Armitage \& Berry (1987). The diurnal variation in EE was analysed by using the method of summary measures (Matthews et al. 1990). Changes in body weight were statistically tested using repeated measures analysis of variance and Scheffé $F$ tests. Correlation between physical activity and EE was quantified using the Pearson correlation coefficient. Data are presented as the mean and standard error of the mean in the text, tables and figures.

\section{RESULTS}

\section{$E I, A D M R$ and $24 h E E$}

EI, ADMR and $24 \mathrm{~h} \mathrm{EE}$ of individual subjects are presented in Table 2. ADMR was not significantly different between the two patterns (gorging pattern 11.8 (SD 1.0$) \mathrm{MJ} / \mathrm{d}$, nibbling pattern $12.3(\mathrm{SD} 1.6) \mathrm{MJ} / \mathrm{d} ; P=0.400$ ). Analysis of $24 \mathrm{~h}$ EE shows that there was no significant effect of meal frequency. Mean $24 \mathrm{~h} \mathrm{EE}$ was 9.4 (SE 0.2) MJ/d for both gorging and nibbling patterns $(P=0.819)$. In both eating patterns $24 \mathrm{~h}$ EE was significantly lower than ADMR (gorging pattern $P=0.0003$, nibbling pattern $P=0.0001$ ), probably because of the restricted physical activity of the subjects while staying in the respiration chamber. Table 3 presents the dilution spaces and fractional elimination rates for ${ }^{18} \mathrm{O}$ and ${ }^{2} \mathrm{H}$.

Mean EI was significantly lower than ADMR, resulting in a negative energy balance in free-living conditions for both gorging (EI-ADMR $=-1.8(\mathrm{SE} 0 \cdot 3) \mathrm{MJ} / \mathrm{d})$ and nibbling patterns $(\mathrm{EI}-\mathrm{ADMR}=-2 \cdot 1(\mathrm{SE} 0 \cdot 6) \mathrm{MJ} / \mathrm{d})$. EI was not significantly different from $24 \mathrm{~h}$ EE on the gorging pattern $(P=0 \cdot 153)$, and significantly higher than $24 \mathrm{~h}$ EE on the nibbling pattern $(P=0.034)$. Therefore, subjects were in a slightly positive energy balance while they were staying in the respiration chamber (gorging pattern $\mathrm{EI}-24 \mathrm{~h} \mathrm{EE}=+0.7$ (SE 0.4) $\mathrm{MJ} / \mathrm{d}$, nibbling pattern $\mathrm{EI}-24 \mathrm{~h} \mathrm{EE}=+0.8($ SE $0 \cdot 3) \mathrm{MJ} / \mathrm{d}$ ).

\section{Diurnal variation in EE}

Fig. 2 shows the individual data for EE on both eating patterns, expressed over $3 \mathrm{~h}$ intervals. The diurnal variation in EE was analysed by dividing the day into two periods of $12 \mathrm{~h}$ : 07.00-19.00 hours and 19.00-07.00 hours. These periods were chosen because 
Table 2. Energy $(M J / d)$ intake $(E I)$ and expenditure $(E E)$ of individual male subjects, fed according to a gorging or a nibbling pattern, measured in free-living conditions (average daily metabolic rate, $A D M R)$ and sedentary conditions in a respiration chamber $(24 \mathrm{~h} \mathrm{EE})^{*}$

\begin{tabular}{|c|c|c|c|c|c|c|}
\hline \multirow[b]{2}{*}{ Subject } & \multicolumn{3}{|c|}{ Gorging pattern } & \multicolumn{3}{|c|}{ Nibbling pattern } \\
\hline & EI & ADMR & $24 \mathrm{~h} \mathrm{EE}$ & EI & ADMR & $24 \mathrm{~h} \mathrm{EE}$ \\
\hline 1 & $9 \cdot 8$ & $11 \cdot 9$ & $10 \cdot 8$ & $9 \cdot 9$ & $15 \cdot 9$ & $10 \cdot 7$ \\
\hline 2 & $10 \cdot 8$ & $11 \cdot 6$ & $9 \cdot 4$ & $10 \cdot 8$ & $11 \cdot 9$ & $9 \cdot 4$ \\
\hline 3 & $9 \cdot 3$ & $11 \cdot 5$ & $8 \cdot 5$ & $9 \cdot 4$ & $10 \cdot 6$ & $8 \cdot 7$ \\
\hline 4 & $11 \cdot 4$ & $12 \cdot 5$ & $9 \cdot 2$ & 11.5 & $12 \cdot 8$ & $9 \cdot 7$ \\
\hline 5 & 8.9 & $10 \cdot 3$ & $10 \cdot 0$ & 9.0 & $12 \cdot 5$ & $9 \cdot 3$ \\
\hline 6 & $8 \cdot 3$ & $11 \cdot 2$ & 9.7 & $9 \cdot 3$ & 11.5 & $9 \cdot 2$ \\
\hline 7 & $8 \cdot 4$ & $12 \cdot 0$ & $8 \cdot 0$ & $8 \cdot 4$ & $11 \cdot 4$ & $8 \cdot 5$ \\
\hline 8 & $11 \cdot 3$ & $13 \cdot 4$ & $9 \cdot 2$ & $11 \cdot 3$ & $10 \cdot 6$ & $9 \cdot 6$ \\
\hline 9 & $10 \cdot 8$ & $10 \cdot 6$ & $9 \cdot 2$ & $10 \cdot 8$ & $12 \cdot 8$ & $9 \cdot 3$ \\
\hline 10 & $11 \cdot 4$ & $12 \cdot 9$ & $9 \cdot 5$ & $11 \cdot 4$ & $13 \cdot 2$ & $9 \cdot 4$ \\
\hline Mean & $10 \cdot 0$ & $11 \cdot 8$ & $9 \cdot 4$ & $10 \cdot 2$ & $12 \cdot 3$ & $9 \cdot 4$ \\
\hline $\mathrm{SE}$ & $0 \cdot 4$ & $0-3$ & $0 \cdot 2$ & 0.4 & $0 \cdot 5$ & 0.2 \\
\hline Difference from EI, $P=$ & & 0.0006 & $0 \cdot 153$ & & 0.004 & 0.034 \\
\hline
\end{tabular}

* For details of diets and procedures, see pp. 104-106.

Table 3. Dilution spaces $(l)$ and daily fractional elimination rates from body water of excess ${ }^{18} \mathrm{O}$ and ${ }^{2} \mathrm{H}$ for individual male subjects during the 2 week experimental period ${ }^{*}$

\begin{tabular}{|c|c|c|c|c|c|c|}
\hline \multirow[b]{2}{*}{ Subject } & \multirow[b]{2}{*}{$\mathrm{D}_{\mathrm{o}}$} & \multirow[b]{2}{*}{$\mathrm{D}_{\mathrm{H}}$} & \multicolumn{2}{|c|}{ Days 1-7 } & \multicolumn{2}{|c|}{ Days $7-15$} \\
\hline & & & $k_{18}$ & $k_{2}$ & $k_{18}$ & $k_{2}$ \\
\hline 1 & $46 \cdot 20$ & 47.03 & 0.09273 & 0.07111 & 0.10347 & 0.07534 \\
\hline 2 & $42 \cdot 53$ & $42 \cdot 54$ & 0.09468 & 0.07179 & 0.09877 & 0.07521 \\
\hline 3 & 35.45 & 36.42 & 0.11180 & 0.08683 & $0 \cdot 11014$ & 0.08344 \\
\hline 4 & 40.53 & 41.63 & $0 \cdot 10473$ & 0.07871 & $0 \cdot 10470$ & 0.07924 \\
\hline 5 & 41.01 & $42 \cdot 50$ & 0.07834 & 0.05792 & 0.08960 & 0.06501 \\
\hline 6 & $38 \cdot 74$ & $40 \cdot 14$ & 0.08038 & 0.05698 & 0.09647 & 0.07184 \\
\hline 7 & $40 \cdot 00$ & $41 \cdot 45$ & 0.11062 & 0.08676 & 0.10954 & 0.08462 \\
\hline 8 & 36.59 & 37.93 & 0.11624 & 0.09184 & 0.12119 & 0.09104 \\
\hline 9 & $36 \cdot 28$ & 37.60 & 0.09723 & 0.07320 & $0 \cdot 10849$ & 0.07970 \\
\hline 10 & $41 \cdot 17$ & $42 \cdot 66$ & 0.13100 & $0 \cdot 10445$ & 0.09650 & 0.07030 \\
\hline
\end{tabular}

$\mathrm{D}_{0}$, dilution space for ${ }^{18} \mathrm{O} ; \mathrm{D}_{\mathrm{H}}$, dilution space for ${ }^{2} \mathrm{H} ; k_{18}$ fractional elimination rate based on excess ${ }^{18} \mathrm{O} ; k_{2}$ fractional elimination rate based on excess ${ }^{2} \mathrm{H}$.

* For details of procedures see pp. 105-106.

subjects rise at 07.00 hours in the morning and $24 \mathrm{~h}$ EE measurements were made between 07.00 and 07.00 hours. From 07.00 to 19.00 hours EE was not significantly different between both patterns (Area Under Curve (AUC) $)_{\text {(gorging) }} 7.00$ (SE 0.20) kJ/min, AUC (nibbling) 7.23 (SE 0.14$) \mathrm{kJ} / \mathrm{min} ; P=0.111$ ). In the period from 19.00 to 07.00 hours $\mathrm{EE}$ was significantly elevated in the gorging pattern $\left(\mathrm{AUC}_{\text {(gorging) }} 6 \cdot 00(\mathrm{SE} 0 \cdot 16) \mathrm{kJ} / \mathrm{min}, \mathrm{AUC}_{\text {(nibbling) }}\right.$ $5.80($ SE 0.13$) \mathrm{kJ} / \mathrm{min} ; P=0.026)$.

\section{Body weight and body composition}

Body weight, FFM and FM over the 2-week experimental period are presented in Table 4 ( $n 9$; data from subject 9 were not complete with respect to body composition 

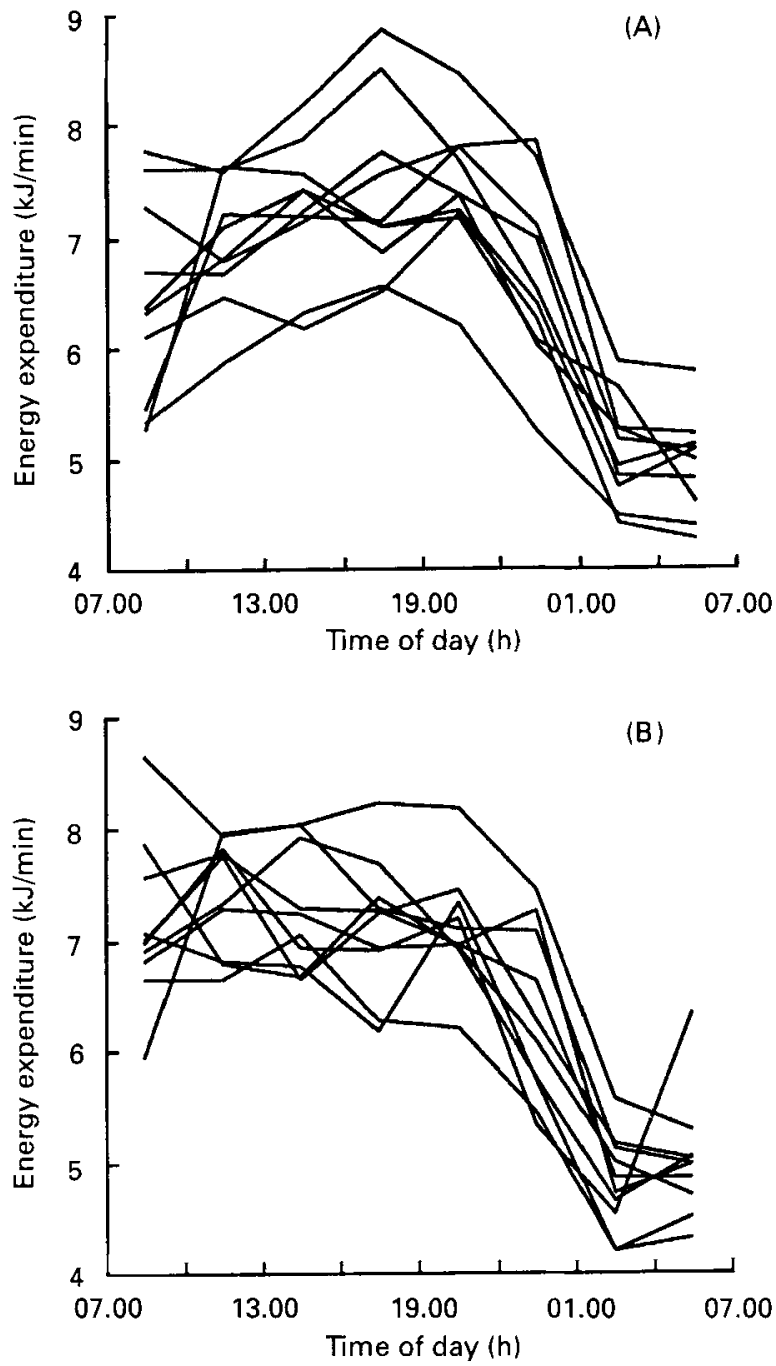

Fig. 2. Individual plots of diurnal energy expenditure as measured in the respiration chamber $(\mathrm{kJ} / \mathrm{min}) v$. time for all ten male adult subjects on a gorging (A) and nibbling (B) pattern.

Table 4. Mean body weight, fat-free mass and fat mass $(\mathrm{kg})$ during the 2-week experimental period*

(Mean values with their standard errors for nine subjects)

\begin{tabular}{|c|c|c|c|c|c|c|}
\hline & \multicolumn{2}{|c|}{ Start } & \multicolumn{2}{|c|}{ After 1 week } & \multicolumn{2}{|c|}{ End } \\
\hline & Mean & SE & Mean & $\mathrm{SE}$ & Mean & $\mathrm{SE}$ \\
\hline Body wt $\dagger$ & 77.0 & $4 \cdot 3$ & $76 \cdot 8$ & $4 \cdot 3$ & $76 \cdot 4$ & $4 \cdot 3$ \\
\hline Fat-free mass & $58 \cdot 7$ & $1 \cdot 4$ & - & - & $58 \cdot 7$ & $1 \cdot 3$ \\
\hline Fat mass & $18 \cdot 3$ & $3 \cdot 2$ & - & - & $17 \cdot 7$ & $3 \cdot 1$ \\
\hline
\end{tabular}

* For details of procedures, see p. 107.

$\dagger$ Body wt repeated measures, $P=0.085$.

\# Fat-free mass at start $v$. fat-free mass at end, $P=0.889$.

$\S$ Fat mass at start $v$. fat mass at end, $P=0.308$. 

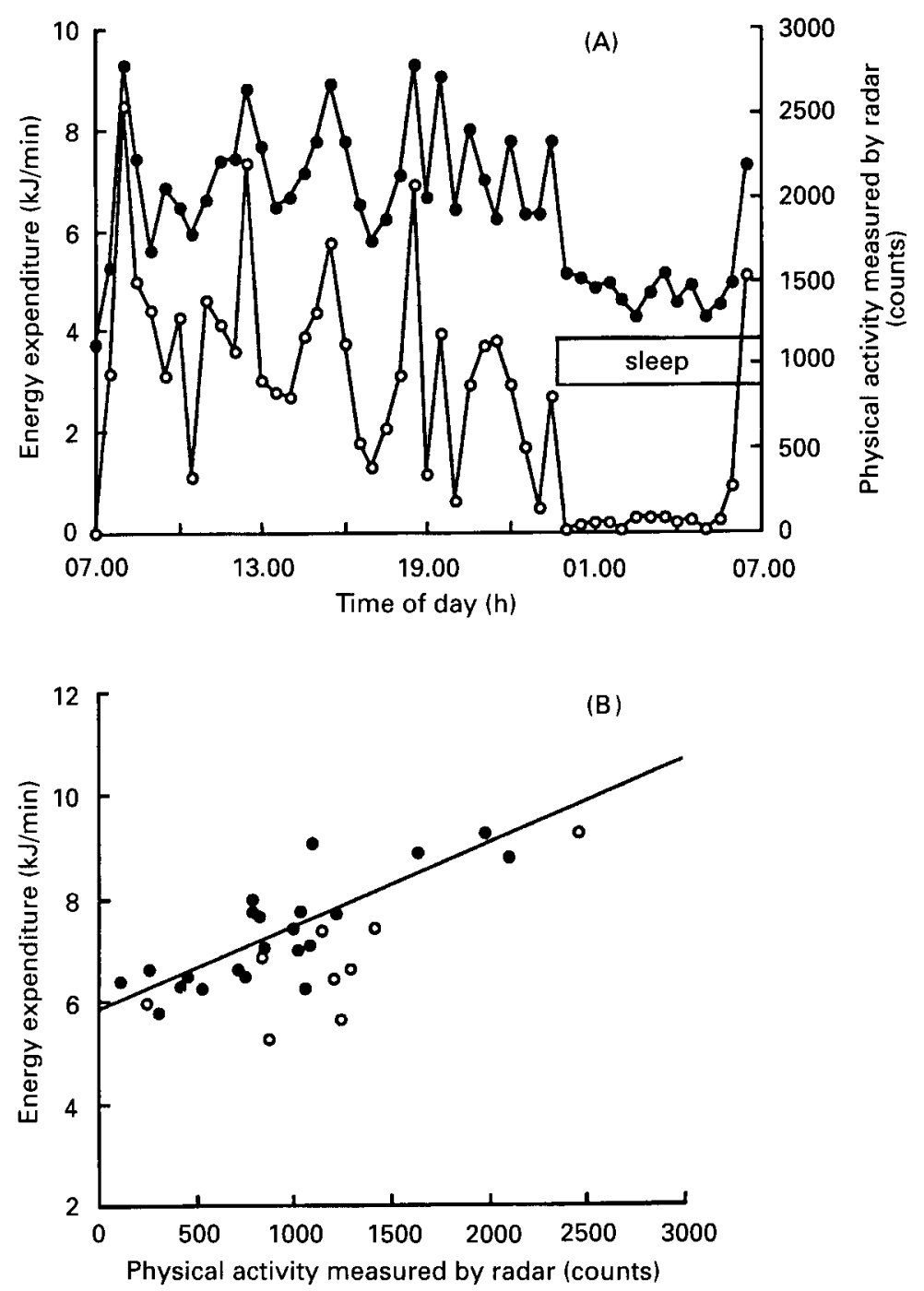

Fig. 3. (A) Energy expenditure (EE) (-O) and physical activity $(\mathrm{O}-\mathrm{O})$ (averaged over $30 \mathrm{~min}$ periods) during the course of the day in one subject (subject 9) on the gorging pattern. (B) Relationship between EE and physical activity in the same subject; each point represents a $30 \mathrm{~min}$ period from 12.00 to 23.00 hours ( $)$ or from 07.30 to 12.00 hours $(\mathrm{O})$. Regression line; $\mathrm{EE}=5.84+1.61 \mathrm{e}^{-3}$ activity (Pearson's $r 0.807, P=0.0001$ ).

measurements). Body weight changes $(-0.6(\mathrm{SE} 0.3) \mathrm{kg} / 14 \mathrm{~d})$ were not significantly different from zero. Weight loss was not associated with the pattern of food intake: 0.3 (SE 0.2) $\mathrm{kg}$ for both gorging and nibbling patterns $(P=0.801)$. FFM and FM did not change significantly during the study. There was a significant relationship (Pearson's $r 0.779, P=0.014)$ between the discrepancy between EI and EE and the change in body weight over the experimental period, in that subjects with the highest energy deficit lost most weight.

\section{$B M R, D I T$ and $A C T$}

Fig. $3 \mathrm{~A}$ shows the diurnal variation in $\mathrm{EE}$ and physical activity of one subject on the gorging pattern. Fig. $3 \mathrm{~B}$ presents the individual regression line of $\mathrm{EE}$ on physical activity 
Table 5. Energy expenditure $(\mathrm{kJ} / \mathrm{min})$ in the inactive state $\left(E E_{0 a c t i v i t}\right)$ for individual male subjects fed according to a gorging or a nibbling pattern

\begin{tabular}{|c|c|c|c|c|c|c|c|c|}
\hline \multirow[b]{3}{*}{ Subject } & \multicolumn{4}{|c|}{ Gorging pattern (df 21) } & \multicolumn{4}{|c|}{ Nibbling pattern (df 30 ) } \\
\hline & \multicolumn{2}{|c|}{$\mathrm{EE}_{\text {oactivity }}$} & \multirow[b]{2}{*}{$r$} & \multirow[b]{2}{*}{$P$} & \multicolumn{2}{|c|}{$\mathrm{EE}_{\text {0activity }}$} & \multirow[b]{2}{*}{$r$} & \multirow[b]{2}{*}{$P$} \\
\hline & Mean & CL & & & Mean & $\mathrm{CL}$ & & \\
\hline 1 & $6 \cdot 66$ & $6 \cdot 04-7 \cdot 28$ & 0.826 & $0 \cdot 0001$ & $6 \cdot 16$ & $5 \cdot 25-7.07$ & 0.691 & $0 \cdot 0001$ \\
\hline 2 & $6 \cdot 38$ & $5 \cdot 85-6 \cdot 91$ & 0.677 & 0.0005 & $6 \cdot 18$ & $5.38-6.98$ & $0 \cdot 551$ & 0.0013 \\
\hline 3 & 6.64 & $5 \cdot 73-7 \cdot 55$ & $0 \cdot 045$ & $0 \cdot 8580$ & 5.67 & $4 \cdot 30-7 \cdot 04$ & $0 \cdot 305$ & $0 \cdot 1084$ \\
\hline 4 & $5 \cdot 88$ & $4.90-6 \cdot 86$ & 0.554 & 0.0075 & $5 \cdot 62$ & $4.64-6.60$ & 0.585 & 0.0005 \\
\hline 5 & 6.07 & $5 \cdot 26-6 \cdot 88$ & 0.783 & 0.0001 & $5 \cdot 41$ & $4 \cdot 61-6 \cdot 21$ & 0.684 & 0.0001 \\
\hline 6 & $6 \cdot 40$ & $5 \cdot 23-7 \cdot 57$ & $0 \cdot 414$ & 0.0558 & $5 \cdot 49$ & $5 \cdot 02-5 \cdot 96$ & 0.835 & 0.0001 \\
\hline 7 & $5 \cdot 43$ & $4 \cdot 65-6 \cdot 21$ & 0.507 & 0.0161 & $5 \cdot 61$ & $496-6 \cdot 26$ & 0.551 & 0.0013 \\
\hline 8 & $6 \cdot 23$ & $5 \cdot 54-6 \cdot 92$ & 0.609 & 0.0026 & 5.89 & $5 \cdot 22-6 \cdot 56$ & 0.709 & 0.0001 \\
\hline 9 & $5 \cdot 84$ & $5 \cdot 27-6 \cdot 41$ & 0.807 & $0 \cdot 0001$ & 5.66 & 5.246 .08 & 0.815 & 0.0001 \\
\hline 10 & 6.75 & $6 \cdot 06-7 \cdot 44$ & 0.516 & 0.0140 & $6 \cdot 11$ & $5 \cdot 71-6 \cdot 51$ & 0.799 & $0.000 \mathrm{I}$ \\
\hline
\end{tabular}

CL, $95 \%$ confidence limits for $\mathrm{EE}_{0 \text { activity }}$.

Table 6. Mean average daily metabolic rate $(A D M R)$, energy expenditure in the inactive state $\left(E E_{0 \text { activity }}\right)$, sleeping metabolic rate $(S M R)$, basal metabolic rate $(B M R)$, diet-induced thermogenesis $(D I T)$ and energy expended on physical activity $(A C T)$ of ten adult male subjects $(M J / d)$ fed according to a gorging or a nibbling pattern*

\begin{tabular}{|c|c|c|c|c|c|}
\hline & \multicolumn{2}{|c|}{ Gorging pattern } & \multicolumn{2}{|c|}{ Nibbling pattern } & \multirow[b]{2}{*}{$P$} \\
\hline & Mean & $\mathrm{SE}$ & Mean & $\mathrm{SE}$ & \\
\hline ADMR & $11 \cdot 8$ & $0 \cdot 3$ & $12 \cdot 3$ & 0.5 & 0.400 \\
\hline $\mathrm{EE}_{\text {factivity }}$ & 90 & 0.2 & $8 \cdot 3$ & $0-1$ & 0.003 \\
\hline SMR & $6 \cdot 7$ & $0 \cdot 1$ & $6 \cdot 6$ & $0 \cdot 1$ & - \\
\hline BMR & $7 \cdot 0$ & $0 \cdot 2$ & 7.0 & $0 \cdot 1$ & 0.690 \\
\hline DIT & $2 \cdot 0$ & $0 \cdot 2$ & $1 \cdot 3$ & $0 \cdot 1$ & 0.008 \\
\hline DIT (corr.) $\dagger$ & $0 \cdot 9$ & $0 \cdot 1$ & 0.9 & $0 \cdot 1$ & 0.778 \\
\hline ACT & 3.9 & $0 \cdot 3$ & $4 \cdot 5$ & $0 \cdot 4$ & $0 \cdot 373$ \\
\hline
\end{tabular}

\footnotetext{
* For details of procedures, see p. 106.

$\dagger$ Corrected for the time interval used for assessment of DIT.

\$ $\mathrm{ACT}=\mathrm{ADMR}-\mathrm{BMR}-\mathrm{DIT}$ (corr.).
}

of the same subject. Only the intervals after the first meal until bedtime were used for assessment of DIT.

Within individuals, EE and physical activity were related significantly except for subject 3 on both the gorging and nibbling patterns and subject 6 on the gorging pattern (Table 5). The effect of meal frequency on ADMR and its components BMR, DIT and ACT is presented in Table 6. ADMR was not significantly different between the two patterns. BMR did not differ between both patterns, while DIT was significantly elevated in the gorging pattern. When correcting for the relevant time interval the effect of meal frequency on DIT was neutralized. DIT (gorging) $=\left(\mathrm{EE}_{\text {0activity }}-\mathrm{BMR}\right) \times 11 / 24($ measured over $11 \mathrm{~h})=$ $0.9(\mathrm{SE} 0 \cdot 1) \mathrm{MJ} / \mathrm{d} ; \mathrm{DIT}_{\text {(nibbling) }}=\left(\mathrm{EE}_{\text {0activity }}-\mathrm{BMR}\right) \times 15 \cdot 5 / 24($ measured over $15.5 \mathrm{~h})=0.9$ (SE $0 \cdot 1) \mathrm{MJ} / \mathrm{d}$. Thus, the contribution of DIT to ADMR was 7.6 (SE 0.8 ) $\%$ for the gorging 
pattern and 7.3 (SE 0.8$) \%$ for the nibbling pattern $(P=0.653)$. ACT was not significantly different between the two patterns.

\section{DISCUSSION}

According to Ravussin et al. (1988) there is an inverse relationship between a reduced $24 \mathrm{~h}$ $\mathrm{EE}$ and the rate of subsequent weight gain. A reduced daily $\mathrm{EE}$ is, therefore, a possible risk factor in the development of obesity. Several studies have investigated the effects of meal frequency on $24 \mathrm{~h} \mathrm{EE}$. Dallosso et al. (1982), studying the effect of meal frequency in adult males, failed to observe an effect on $24 \mathrm{~h}$ EE. Their study showed an alteration of the profile of EE over the day with changing meal frequency, but the differences balanced themselves out. According to Wolfram et al. (1987) there was no influence of meal frequency on energy balance in adolescents, studied under the condition of slight undernutrition. In the present study there was no significant effect of meal frequency on ADMR or $24 \mathrm{~h}$ EE. Therefore, the greater percentage of overweight and adiposity in gorging people, as observed in epidemiologic studies (Fábry et al. 1964, 1966; Hejda \& Fábry, 1964; Metzner et al. 1977), cannot, according to the present study, be explained by a decrease in daily EE.

In the present study there was a significant decrease in $24 \mathrm{~h}$ EE compared to ADMR for both gorging (20.1 (SE 3.2) \%) and nibbling patterns (23.2 (SE 2.1) \%) due to the restriction of spontaneous physical activity of the subjects while staying in the respiration chamber. Because EI was not adjusted for this decrease in EE, differences in energy balance between free-living and sedentary conditions are to be expected. There are two possible reasons for the deficit between diary-estimated energy requirements and actual requirements. One is that subjects may have underreported their EI. Prentice et al. (1986) described a mean difference of $33 \%$ between reported EI and measured EE for obese subjects, while the corresponding difference for lean subjects was only $2 \%$. However, subjects in the present study were not expected to have any reasons for intentional underreporting. A second possibility might be a negative influence of keeping a dietary record on habitual EI. In fact, several of the subjects studied reported that having to record all they ate and drank for $7 \mathrm{~d}$ changed their feeding habits, i.e by unintended restriction of their EI.

The study design employed a crossover of dietary treatments, with the order of administration randomized. It is important in such cases to consider the possibility of a carry-over effect of the first treatment into the second half of the study. There are indications, however, that people can adjust in a relatively short period of time to changes in EI. Hill et al. (1991) conducted a study to determine whether substrate oxidation is influenced by changes in diet composition over a $7 \mathrm{~d}$ interval. The results showed that there were no significant changes in measured variables on days 3 and 7 , indicating a rapid adjustment (within $3 \mathrm{~d}$ ) of the body to changes in EI, i.e. diet composition. Concerning the experimental design of this study, we hypothesized that our subjects also adjusted in a short period of time to the eating pattern administered and assume that the carry-over effect was unimportant in this study.

As we used a single dose of doubly-labelled water to measure ADMR, it is important to consider the possibility that reduced isotopic enrichment affected precision of the measurements during the second $7 \mathrm{~d}$ period. According to Schoeller (1983), the optimal metabolic period to measure EE in human adults is $5-28 \mathrm{~d}$. Taking the biological half-life of ${ }^{18} \mathrm{O}$ to be about $7 \mathrm{~d}$, a calculated ${ }^{18} \mathrm{O}$ excess of 300 p.p.m. would be produced in week 1 of the study and one of 150 p.p.m. in week 2 . This would mean that during week 2 the measurement of ADMR is less precise. Schoeller (1983) estimated the precision of ADMR as $\pm 3 \%$ in week 1 . v. $\pm 7 \%$ in week 2 . However, randomization of the presentation of dietary patterns should balance the difference in precision across the study group. 
Studies of the effect of meal frequency on the energy components BMR, DIT and ACT have been inconsistent. According to Swindells et al. (1968) there was no difference in resting $\mathrm{O}_{2}$ consumption of young women when daily EI was consumed in two or nine meals daily. Some studies reported an increased DIT with a gorging pattern of food intake (Molnár, 1990; Tai et al. 1990) while others described no relationship (Belko \& Barbieri, 1987; Kinabo \& Durnin, 1990). The time interval used for determination of DIT in these studies ranged from 5 to $10 \mathrm{~h}$, as well as the number of meals indicated as 'gorging' (one to two meals) or 'nibbling' (two to six meals). Miller \& Wise (1975) and ZahorskaMarkiewicz (1980) suggested that an interaction of the physical activity of the subjects and DIT could be of great importance in regulating EE.

Our findings indicated no influence of meal frequency on BMR. $E_{0 \text { activity }}$ was significantly elevated in the gorging pattern due to an increased DIT. However, when correcting the data on DIT for the relevant time interval, the effect of meal frequency was neutralized. Fig. $3 \mathrm{~B}$ shows the relationship between physical activity and EE in a subject on the gorging pattern. The data from the preprandial period (i.e. from 07.30 to 12.00 hours) are localized beneath the regression line, indicating that it is justified to exclude these points from regression analysis. Furthermore, we expect no contribution to DIT during the preprandial period of the gorging pattern. Considering the data on diurnal variation in EE (Fig. 2), we suggest that the contribution of DIT in the gorging pattern was continued till the early night, reflected by a greater AUC from 19.00 to 07.00 hours which could not be explained by a change in physical activity. Thus, despite the fact that subjects following the nibbling pattern consumed an evening snack at 20.30 hours, EE from 19.00 to 07.00 hours was still significantly higher for the gorging pattern. Fábry (1973) suggested that if a gorging pattern of food intake leads to an inhibition of spontaneous physical activity ('laziness' after a rich meal) this inhibition can vary greatly, depending on a subject's baseline activity. In the present study there was no effect of meal frequency on the contribution of ACT to ADMR, but we have no information about the general level of activity of the subjects under free-living conditions. Measurements of physical activity in sedentary conditions in the respiration chamber, determined by means of a radar system, revealed that there was no difference in physical activity between gorging (701 (SE 48) counts $/ 24 \mathrm{~h}$ ) and nibbling pattern (749 (SE 34) counts/24 h; $P=0.243$ ).

In conclusion, no significant effect of meal frequency on ADMR or $24 \mathrm{~h}$ EE was observed. The contribution of DIT to ADMR was significantly increased in the gorging pattern. However, when the relevant time interval for DIT was taken into account the effect of meal frequency was neutralized. BMR and ACT were not significantly different between the gorging and nibbling patterns. We can only speculate about the reasons for these findings. One could imagine that the effect of meal frequency is more obvious when subjects are accustomed to a gorging or nibbling pattern of food intake. If this is the case, further investigation is necessary. Considering the results of other studies on the effect of meal frequency on human energy metabolism (Dallosso et al. 1982; Wolfram et al. 1987; Verboeket-van de Venne \& Westerterp, 1991) and the results of the present study (also focussing on $\mathrm{EE}$ in free-living conditions), a more likely conclusion may be that meal frequency has no effect at all on total daily EE.

\section{REFERENCES}

Armitage, P. \& Berry, G. (1987). Statistical Methods in Medical Research, pp. 224-225. Oxford: Blackwell Scientific.

Belko, A. Z. \& Barbieri, T. F. (1987). Effect of meal size and frequency on the thermic effect of food. Nutrition Research 7, 237-242. 
Cohn, C. (1964). Feeding patterns and some aspects of cholesterol metabolism. Federation Proceedings 23, 76-81.

Cohn, C., Joseph, D., Bell, L. \& Allweiss, M. D. (1965). Studies on the effects of feeding frequency and dietary composition on fat deposition. Annals of the New York Academy of Sciences 131, 507-518.

Dallosso, H. M., Murgatroyd, P. R. \& James, W. P. T. (1982). Feeding frequency and energy balance in adult males. Human Nutrition: Clinical Nutrition 36C, 25-39.

Debry, G., Rohr, R., Azouaou, R., Vassilitch, I. \& Mottaz, G. (1973). Ponderal losses in obese subjects submitted to restricted diets differing by nibbling and by lipid and carbohydrate. In Energy Balance in Man, pp. 305-310 [M. Apfelbaum, editor]. Paris: Masson.

Fábry, P. (1973). Food intake pattern and energy balance. In Energy Balance in Man, pp. 297-303 [M. Apfelbaum, editor]. Paris: Masson.

Fábry, P., Fodor, J., Hejl, Z., Braun, T. \& Zvolánková, K. (1964). The frequency of meals: its relationship to overweight, hypercholesterolaemia, and decreased glucose tolerance. Lancet 2, 614-615.

Fábry, P., Hejda, S., Cerny, K., Osancová, K. \& Pechar, J. (1966). Effect of meal frequency in school children. Changes in the weight-height proportion and skinfold thickness. American Journal of Clinical Nutrition 18 , $358-361$.

Fábry, P. \& Tepperman, J. (1970). Meal frequency - a possible factor in human pathology. American Journal of Clinical Nutrition 23, 1059-1068.

Flatt, J. P. (1987). Dietary fat, carbohydrate balance, and weight maintenance: Effects of exercise. American Journal of Clinical Nutrition 45, 296-306.

Goldberg, G. R., Prentice, A. M., Davies, H. L. \& Murgatroyd, P. R. (1988). Overnight and basal metabolic rates in men and women. European Journal of Clinical Nutrition 42, 137--144.

Gwinup, G., Byron, R. C., Roush, W. H., Kruger, F. A. \& Hamwi, G. J. (1963a). Effect of nibbling versus gorging on serum lipids in man. American Journal of Clinical Nutrition 13, 209-213.

Gwinup, G., Byron, R. C., Roush, W. H., Kruger, F. A. \& Hamwi, G. J. (1963b). Effect of nibbling versus gorging on glucose tolerance. Lancet 2, 165-167.

Hejda, S. \& Fábry, P. (1964). Frequency of food intake in relation to some parameters of the nutritional status. Nutritio et Dieta 6, 216.

Hill, J. O., Peters, J. C., Reed, G. W., Schlundt, D. G., Sharp, T. \& Greene, H. L. (1991). Nutrient balance in humans: effects of diet composition. American Journal of Clinical Nutrition 54, 10-17.

Huenemann, R. L. (1972). Food habits of obese and non-obese adolescents. Postgraduate Medicine 51, 99-105.

Huenemann, R. L., Hampton, M. C., Shapiro, L. R. \& Behnke, A. R. (1966). Adolescent food practices associated with obesity. Federation Proceedings 25, 4-10.

Irwin, M. I. \& Feeley, R. M. (1967). Frequency and size of meals and serum lipids, nitrogen and mineral retention, fat digestibility, and urinary thiamine and riboflavin in young women. American Journal of Clinical Nutrition 20, 816-824.

Jagannathan, S. N., Connell, W. F. \& Beveridge, J. M. R. (1964). Effects of gourmandizing and semicontinuous eating of equicaloric amounts of formula-type high fat diets on plasma cholesterol and triglyceride levels in human volunteer subjects. American Journal of Clinical Nutrition 15, 90-94.

Kinabo, J. L. D. \& Durnin, J. V. G. A. (1990). Effect of meal frequency on the thermic effect of food in women. European Journal of Clinical Nutrition 44, 389-395.

Leveille, G. A. (1970). Adipose tissue metabolism: Influence of periodicity of eating and diet composition. Federation Proceedings 29, 1294-1301.

Matthews, J. N. S., Altman, D. G., Campbell, M. J. \& Royston, P. (1990). Analysis of serial measurements in medical research. British Medical Journal 300, 230-235.

Metzner, H. L., Lamphiear, D. E., Wheeler, N. C. \& Larkin, F. A. (1977). The relationship between frequency of eating and adiposity in adult men and women in the Tecumseh Community Health Study. American Journal of Clinical Nutrition 30, 712-715.

Miller, D. S. \& Wise, A. (1975). Exercise and dietary-induced thermogenesis. Lancet 1, 1290.

Molnár, D. (1990). The effect of meal frequency on postprandial thermogenesis in obese children. International Journal of Obesity 14 Suppl. 2, 95.

Prentice, A. M., Black, A. E., Coward, W. A., Davies, H. L., Goldberg, G. R., Murgatroyd, P. R., Ashford, J., Sawyer, M. \& Whitehead, R. G. (1986). High levels of energy expenditure in obese women. British Medical Journal 292, 983-987.

Ravussin, E., Lillioja, S., Knowler, W. C., Christin, L., Freymond, D., Abbott, W. G. H., Boyce, V., Howard, B. V. \& Bogardus, C. (1988). Reduced rate of energy expenditure as a risk factor for body-weight gain. New England Journal of Medicine 318, 467-472.

Schoeller, D. A. (1983). Energy expenditure from doubly labelled water: some fundamental considerations in humans. American Journal of Clinical Nutrition 38, 999-1005.

Schoeller, D. A., Van Santen, E., Peterson, D. W., Dietz, W., Jaspan, J. \& Klein, P. D. (1980). Total body water measurement in humans with ${ }^{18} \mathrm{O}$ and ${ }^{2} \mathrm{H}$ labelled water. American Journal of Clinical Nutrition 33, $2686-2693$.

Schoffelen, P. F. M., Saris, W. H. M., Westerterp, K. R. \& Ten Hoor, F. (1984). Evaluation of an automatic indirect calorimeter for measurement of energy balance in man. In Human Energy Metabolism: Physical Activity and Energy Expenditure Measurements in Epidemiological Research based upon Direct and Indirect Calorimetry. Euro Nut Report 5, pp. 51-54 [A. J. H. Van Es, editor]. Wageningen: The Netherlands Nutrition Foundation. 
Schutz, Y., Bessard, T. \& Jéquier, E. (1984). Diet-induced thermogenesis measured over a whole day in obese and nonobese women. American Journal of Clinical Nutrition 40,542-552.

Swindells, Y. E., Holmes, S. A. \& Robinson, M. F. (1968). The metabolic response of young women to changes in the frequency of meals. British Journal of Nutrition 22, 667-680.

Tai, M., Castillo, P. \& Pi-Sunyer, F. X. (1990). Effect of nibbling versus gorging on the thermic effect of food (TEF). American Journal of Clinical Nutrition 51 Suppl., 526.

Tepperman, J. \& Tepperman, H. M. (1970). Gluconeogenesis, lipogenesis and the Sherringtoman metaphor. Federation Proceedings 29, 1284-1293.

Terpstra, J., Hessel, L. W., Seepers, J. \& Van Gent, C. M. (1978). The influence of meal frequency on diurnal lipid, glucose and cortisol levels in normal subjects. European Joumal of Clinical Investigation 8, 61-66.

Verboeket-van de Venne, W. P. H. G. \& Westerterp, K. R. (1991). Influence of the feeding frequency on nutrient utilization in man: Consequences for energy metabolism. European Journal of Clinical Nutrition 45, 161-169.

Weir, J. B. de V. (1949). New methods for calculating metabolic rate with special reference to predict protein metabolism. Journal of Physiology 109, 1-9.

Westerterp, K. R. \& Saris, W. H. M. (1991). Limits of energy turnover in relation to physical performance, achievement of energy balance on a daily basis. Joumal of Sports Sciences $9,1-15$.

Westerterp, K. R., Saris, W. H. M., Van Es, M.\& Ten Hoor, F. (1986). Use of the doubly labelled water technique in humans during heavy sustained exercise. Journal of Applied Physiology 61, 2162-2167.

Wolfram, G., Kirchgeßner, M., Müller, H. L. \& Hollomey, S. (1987). Thermogenese des Menschen bei unterschiedlicher Mahlzeitenhäufigkeit (Influence of meal frequency on energy balance in humans). Annals of Nutrition and Metabolism 31, 88-97.

Young, C. M., Hutter, L. F., Scanlan, S. S., Rand, C. E., Lutwak, L. \& Simko, V. (1972). Metabolic effects of meal frequency on normal young men. Journal of the American Dietetic Association 61, 391-398.

Zahorska-Markiewicz, B. (1980). Thermic effect of food and exercise in obesity. European Journal of Applied Physiology 44, 231-235. 